ojs.uv.es/index.php/qdfed

Rebut: 02.06.2020. Acceptat: 07.07.2020

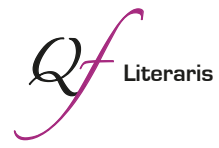

Per a citar aquest article: Poch Olivé, Dolors. 2020. "Estudios fónicos y crítica como sabotaje: recitación poética y afepto". Quaderns de Filologia: Estudis Literaris XXV: 97-Io8.

doi: $10.7203 /$ qdfed.25.I 8986

\title{
Estudios fónicos y crítica como sabotaje: recitación poética y afepto
}

\section{Phonic Studies and the theory of la crítica como sabotaje: poetic recitation} and the afepto

\author{
Dolors Poch Olivé \\ Universitat Autònoma de Barcelona \\ dolors.poch@uab.cat
}

Resumen: En este artículo se analizan las relaciones que se pueden establecer entre los estudios fónicos tradicionales y la teoría de la crítica como sabotaje con el objetivo de establecer puentes entre ambos. A partir del modelo de mundo que se encuentra en la obra de Jaime Gil de Biedma, y mediante el análisis de cuatro versiones recitadas de uno de sus poemas y de tres versiones musicadas de este, se pone de relieve que las formas que adopta el afepto tienen una clara influencia sobre el modelo de mundo que cada versión comunica.

Paraules clau: Estudios fónicos, Crítica como sabotaje, Afepto.

Abstract: This paper analyzes the relationships that can be established between traditional phonic studies and the theory of la critica como sabotaje in order to build bridges between them. Basing upon the model of world that we find in the work of Jaime Gil de Biedma, and through the analysis of four recited and three sung versions of one of his poems, it is highlighted that the forms of the afepto have clear influence on the model of the word expressed by each version. Keywords: Phonic studies, Crítica como sabotaje, Afepto. 


\section{Introducción}

El concepto de afepto es una de las principales aportaciones conceptuales realizadas en el marco de la teoría y de la metodología de la crítica como sabotaje. El término afepto designa el mecanismo transaccional silogístico mediante el cual un texto literario transmite un modelo de mundo, aunando conceptos y afectos. Asensi (20II: 26-5I) señala que el modelo de mundo que figura en el texto literario llega al lector, no como una imposición, no como un discurso de carácter referencial, sino a través de una estructura silogística que tiene efectos performativos:

[...] si atendemos a la manera como funciona un texto artístico, advertiremos que se corresponde a lo que podemos denominar "silogismo afectivo" [...] No estoy argumentando nada parecido a que en un texto artístico tengamos dos dimensiones separadas: el silogismo como estructura profunda y la forma afectiva como estructura superficial, porque uno y otro plano son inseparables y constituyen una de las características más acusadas de la literatura y el arte en general. En realidad, la expresión "silogismo afectivo" describe una unidad funcional de la que depende, eso sí, la efectividad de su modelización (Asensi: 20II: 32).

Y, el mismo autor, en un trabajo más reciente, señala:

[...] sostenemos que, en el caso de los textos artísticos, es, en general, el afepto (neologismo proveniente de los términos "concepto" y "afecto") el que produce el modelo de mundo (Asensi, 2016: 4I).

Uno de los objetivos de la crítica como sabotaje es poner de relieve este juego dialéctico presente en el texto y hacer ver los mecanismos retóricos que lo hacen posible, superando a las teorías más "contenidistas", que ya habían puesto el acento en el poder modelizador de los discursos, como el feminismo, el poscolonialismo o los estudios culturales, pero que habían dejado de lado los mecanismos que lo hacían posible. Desde esta perspectiva crítica, son numerosos los estudios que han analizado distintos corpus textuales desde la crítica como sabotaje (véase Ferrús \& Zabalgoitia, 2013), pero son muy pocos los que se han interesado por el plano fónico, o dicho en otros términos, los que se han interesado por los recursos fónicos de los que se sirve el afepto de un texto.

En este trabajo se abordarán las relaciones que se pueden establecer entre la crítica como sabotaje y los estudios fónicos, detallando posibles recorridos de 
estudio y reflexión. Para ello se analizarán siete versiones diferentes del poema de Jaime Gil de Biedma "No volveré a ser joven". La primera de ellas es la recitada por el propio poeta, otras tres son recitadas por actores o narradores cuentacuentos y, finalmente, el resto son versiones cantadas por intérpretes de reconocido prestigio. Ello permitirá explorar los vínculos entre afepto y sonoridad y establecer relaciones entre los enfoques tradicionales de la fonética, especialmente en torno al estudio de las relaciones entre texto poético y recitación, y la crítica como sabotaje. Como se verá, la sonoridad del mensaje puede ser decisiva en la transmisión de significados y de modelos de mundo.

\section{El plano de la expresión desde el punto de vista de los estudios fónicos}

El significado añadido que pueden aportar los sonidos a la obra literaria, especialmente en el caso de la poesía, ha sido utilizado a lo largo de los siglos por numerosos autores. Uno de los casos más significativos es el del poeta latino Virgilio. M. ${ }^{a}$ José Vega, en su libro El artificio secreto (I992), estudia la historia de la figura retórica denominada aliteración y muestra el uso que hacía Virgilio del valor semántico de los sonidos y su dominio de ese artificio secreto, de alguna manera emboscado, encubierto, que provocaba admiración a quienes oían recitar las obras del poeta facilitándoles así la adhesión al modelo de mundo transmitido por su poesía. La perspectiva de análisis de la teoría de la crítica como sabotaje consideraría, en este caso, que el rendimiento estilístico del sonido verbal estaría en la base del afepto, del silogismo imaginativo que conmueve a los oyentes y les ayuda a penetrar en el modelo de mundo del poeta.

Desde el punto de vista estrictamente formal, los textos poéticos se basan en la utilización de recursos sonoros: la rima, el ritmo, que tiene muy en cuenta la colocación de los acentos en el verso, los encabalgamientos, las estrofas, etc. Cada época de la historia literaria ha privilegiado un uso determinado de los recursos fónicos, pero siempre han estado en la base de la construcción formal de un poema (Clavería - Poch, 20I0). Si bien actualmente la forma más habitual de lectura es la lectura silenciosa, debe considerarse que dicha práctica es relativamente reciente, como lo demuestran los trabajos de Margit Frenck (I997) sobre la lectura en el Siglo de Oro. Por tanto, los textos literarios eran escuchados, cuando alguien los leía en voz alta, con mucha mayor frecuencia que leídos, al revés de como ocurre en la actualidad. Así, los efectos sonoros introducidos en ellos cobraban todo su sentido y eran fácilmente apreciados por los oyentes. Jorge Guillén señalaba a este respecto en ig6r que 
[...] los poemas no existen más que en la voz y no logran su plenitud sino merced a la lectura de viva voz. Esta realidad del sonido es inseparable de la idea, naturalmente, y la idea no alcanza su propio grado de vigor poético sin su encarnación sonora y sus matices muy precisos (743)

Pero estas observaciones no se limitan a los textos poéticos. El trabajo ya clásico de Tomás Navarro Tomás La voz y la entonación en los personajes literarios (1976), en el que el autor hace hincapié en la necesidad de que los escritores den voz propia a sus personajes, realiza un itinerario por la historia de la literatura española mostrando cómo lo consiguen numerosos escritores de distintas épocas. Tan importante es el habla de los personajes de las novelas que el autor afirma: "Un personaje sin voz es tan anormal en la novela como lo sería en la vida corriente” (i976: 8).

Se ha apuntado en la introducción de este trabajo que la sonoridad cumple una función decisiva en la transmisión de significados y los ejemplos aportados ponen de relieve que los estudios fónicos se han interesado mucho por esta cuestión. Se intentará, a continuación, establecer la complementariedad entre la perspectiva de los estudios fónicos y la de la crítica como sabotaje sobre la base de la poesía de Jaime Gil de Biedma.

\section{El modelo de mundo de Jaime Gil de Biedma}

En una entrevista al poeta, realizada en I972 y recogida en el volumen Conversaciones (2002), a la pregunta formulada por el periodista sobre si el paso del tiempo es uno de los temas obsesivos de su poesía, Jaime Gil de Biedma ofrece una respuesta contundente: "En mi poesía no hay más que dos temas: el paso del tiempo y yo" (4I). Las alusiones a dichos temas están presentes en su obra desde el primero de sus libros, Compañeros de viaje (I959), pero aumentan considerablemente y son mucho más claras en Moralidades (I966) y en Poemas póstumos (ig68). En su volumen sobre la Escuela de Barcelona, Carme Riera sitúa a Gil de Biedma, junto a Gabriel Ferrater, otro de los principales exponentes de su generación, en el ámbito de la poesía de la experiencia:

Ambos pueden considerarse poetas de la experiencia [...] ambos rechazan el surrealismo sin paliativos [...] y abogan en favor de la racionalidad. Los dos se preocupan por el tono del poema, por la búsqueda de la voz y el modo de decir más adecuado para cada situación poética [...] Y cultivan el distanciamiento irónico [...] y prefieren la actitud moral [...] (Riera, I988: 60-6I). 
James Valender (2006), en el prólogo a su edición de Las personas del verbo desgrana algunas de las características de la poesía de la experiencia en la poética de Gil de Biedma:

La experiencia de la que tanto se habla, es algo que el mismo poema crea. Lejos de someterse a tal o cual carga emotiva o mensaje intelectual, el poeta mira críticamente los estímulos que la memoria y el intelecto le deparan: los mide y los valora. De tal manera que la experiencia que se comunica al lector es, más que el mero recuerdo de tal o cual episodio, el proceso mismo de medir y valorar el significado que ese episodio pudiera tal vez tener, tanto para el propio poeta como para su posible lector (2006: 9).

Así, Gil de Biedma construye un modelo de mundo en el que dominan dos preocupaciones, los dos temas que él mismo explicita, a través de reflexiones sobre el efecto que el paso del tiempo origina en el individuo e insistiendo en numerosas ocasiones en los cambios que se producen en el paso de la juventud a la madurez, casi al inicio de la vejez. Básicamente trata la cuestión de la llegada de la decrepitud de la mano del paso del tiempo e invita al lector a una reflexión sobre ello que le conducirá a aceptar una visión del mundo como la que propone en su obra.

Uno de los grandes principios en todo modelo de mundo es la relación vida/muerte y, por ende, la reflexión sobre el tema del paso del tiempo y de la vejez. La clásica obra de Cicerón De Senectute (20I8) realiza una apología de la vejez, época de la vida que asimila a la sabiduría y a la capacidad de los mayores de enseñar a las jóvenes generaciones. Es esta una perspectiva que se ha mantenido a lo largo de los siglos en muchas culturas, pero también pueden encontrarse otras visiones. Gonzalo Pontón (2010) estudia una carta de Fernando de Pulgar (de I482) sobre los males de la vejez. El autor muestra que Pulgar, remedando a Cicerón, escribe una epístola sobre el tema pero de carácter muy distinto, pues el modelo de mundo que transmite concibe la última etapa de la vida como una tragedia debido a los achaques y enfermedades que, durante ella, es necesario soportar. La visión de Gil de Biedma entronca con estos planteamientos pero su modelo es diferente: siendo consciente de que el paso de la juventud a la vejez implica muchas pérdidas físicas acepta envejecer y acepta la llegada de la muerte con una visión serena ya que sabe que esa es, en el fondo, la naturaleza de la vida: "envejecer, morir, es el único argumento de la obra" (2006: 194). 
Hemos tomado aquí la noción, en el sentido propuesto por el propio Asensi, como figura que nos permite determinar las coordenadas de un sistema modelizante y ponerlo en diálogo con otros sistemas modelizantes:

La clave de esa capacidad performativa reside precisamente en el hecho de que el modelo de mundo no es el mundo, sino como hemos dicho unas líneas más arriba, una versión del mundo determinada por una posición suturada del sujeto autor (Asensi, 20I2: 2I).

\section{El afepto en "No volveré a ser joven"}

Uno de los poemas emblemáticos de Gil de Biedma es el titulado "No volveré a ser joven", publicado en Poemas póstumos (I968). Es esta una composición extraordinariamente difundida y conocida porque, como puede apreciarse, recoge los dos temas básicos del poeta y establece una estrecha relación entre ellos. De este poema existen cientos de versiones recitadas y cantadas y el propio escritor dice de él que considera que es el mejor poema que ha escrito (https://www.youtube.com/watch?v=NjCYZo_nVDQ). Todo este material, como se indicará con precisión, es de fácil acceso en youtube y, por tanto, ello ha contribuido a constituir, con una relativa facilidad. un corpus que sirva como ejemplo del funcionamiento del afepto en la recitación poética. El texto del poema, que se incluye a continuación, procede de la edición de Valender (2006: I94) y, como se aprecia con sencillez, una de las características principales del plano de la expresión de este es el hecho de que el lenguaje utilizado por el poeta es coloquial y trata el tema como una reflexión que mueve (como un performativo) al lector a reflexionar en el mismo tono en el que está escrita la composición:

Que la vida iba en serio uno lo empieza a comprender más tarde - como todos los jóvenes, yo vine a llevarme la vida por delante.

Dejar huella quería

y marcharme entre aplausos

- envejecer, morir, eran tan sólo

las dimensiones del teatro.

Pero ha pasado el tiempo

y la verdad desagradable asoma: 
envejecer, morir,

es el único argumento de la obra.

El tono utilizado por el poeta es el que corresponde al lenguaje coloquial con el que está construido el poema: una reflexión moderada, sin ninguna tendencia a la declamación, una reflexión formulada, podría decirse, desde la razón. La colocación de los acentos y de las pausas en la recitación respeta escrupulosamente la estructura formal del poema y, en ningún momento aparecen en el recitado variaciones entonativas muy marcadas que denotarían una forma de transmitir las emociones que se alejaría claramente de las pautas que marca el texto. Desde esta perspectiva, Gil de Biedma, como autor del texto, se ciñe a la forma que ha ideado para este y en su afepto transmite sus reflexiones sobre el paso del tiempo y sobre el envejecer e invita al lector a hacer lo mismo y en el mismo tono.

Las otras tres recitaciones del poema que se comentan a continuación presentan una serie de variaciones importantes en sus características, que introducen significados diferentes y transmiten al oyente nuevos matices semánticos, variando el afepto. Así por ejemplo, la versión recitada por el conocido actor Gonzalo de Castro (https://www.youtube.com/watch?v=EGN-cVssLbc) contiene un añadido efecto de eco que produce la impresión de que quien recita se encuentra en un gran espacio vacío que otorga profundidad a la voz y a la recitación, de forma que el oyente percibe una solemnidad que no existe en la versión del autor. Tampoco se encuentra ninguna pista de esta supuesta necesidad de solemnidad en el texto escrito del poema: es muy difícil, por no decir imposible, que el lenguaje coloquial reclame solemnidad. El efecto performativo sobre el lector, provocado por el recurso auditivo del eco no parece invitar a reflexionar, sino que más bien parece querer atemorizar, sumirse en el miedo a envejecer y a morir. El afepto, en este caso, modifica claramente el significado del poema, nos desplaza hacia otro modelo de mundo, sabotea el mensaje original para proponer otra cosa. Si Gil de Biedma plantea una cosmovisión donde vejez y muerte forman parte del ciclo de la vida, la simple transformación de los recursos auditivos invita a imaginar a la muerte con su guadaña, como enemiga del hombre y de la vida, como su amenaza, y a la vejez como un fracaso.

El tercer ejemplo seleccionado para comentar es la recitación de Pilar de los Llanos Joya, youtuber que mantiene un canal en el que publica poemas recitados de muchos autores y de distintas épocas. Su versión de "No volveré a ser joven" puede consultarse en: https://www.youtube.com/watch?v=segqk98o_yE. 
Su recitado se caracteriza por contener música de fondo, música de piano, una melodía muy lenta cuyo volumen está siempre por debajo de aquel al que se escucha la voz. A este efecto se suma, igual que en el caso anterior, el efecto eco que, de nuevo, añade solemnidad. Además, debe señalarse que Pilar Joya introduce unas pausas totalmente inesperadas en su lectura como, por ejemplo, en: "Como todos los jóvenes yo vine a llevarme // la vida por delante", "las dimensiones // del teatro", "es el único argumento // de la obra". Se trata de una distorsión del ritmo natural de lectura que se desprende del texto que afecta también a la estructura entonativa del conjunto de la recitación, pues introducir estas pausas en lugares inapropiados obliga a modificar las variaciones tonales también de una forma inesperada. Por tanto, el significado del poema se ve alterado por la utilización de estas modificaciones del plano de la expresión. La audición del poema en la versión de Pilar Joya invita a considerar que hay una intención clara en su versión: transmitir al lector "su interpretación” (modelo de mundo) del poema. La música, el eco, las pausas y las variaciones entonativas introducen una serie de elementos entre el objeto poético construido por Gil de Biedma y el objeto ofrecido al lector por Pilar Joya. La apelación a los sentimientos, mediante el efecto eco, las pausas y las inflexiones melódicas, en vez de apelar a la reflexión al oyente constituye la gran diferencia en el manejo del afepto entre la versión de Gil de Biedma y la de Pilar Joya. Esta transformación, de nuevo, varía el modelo de mundo del poema original para conducirnos a un universo donde vejez y muerte parecen ahora casi ser apeladas con alegría, como si entre mensaje y tono se produjera una bifurcación o disonancia, pues desde la juventud la muerte y la vejez quedan muy lejos, los mensajes ancestrales sobre ellas emergen como extraña letanía.

El cuarto y último ejemplo de recitación que se comentará es la versión de "No volveré a ser joven" que ofrece Tomás Galindo (https://www.youtube. com/watch?v=zwhRIq4GG-g), que mantiene un canal de youtube en el que recita poemas y narraciones. No hay fondo musical en esta versión pero sí el efecto de eco. En este caso, además, dado que la voz de quien recita es, de por sí, muy grave, este efecto proporciona una profundidad que casi se podría calificar de lúgubre. Además, en la parte final del recitado, Tomás Galindo introduce las siguientes pausas: "Envejecer // morir // es // el único // argumento de la obra”. La solemnidad proporcionada por el efecto eco y por estas pausas constituye, de nuevo, una muestra de la utilización del afepto para transmitir al oyente la interpretación del poema de la persona que lo recita, sus variantes sobre el modelo de mundo inicial. En este caso, los matices 
añadidos van en el sentido de otorgar a la composición un valor de lobreguez, oscuridad, probablemente conectado con el hecho de mencionar la muerte y subrayar esa idea mediante las pausas que se han indicado, en el último verso del poema. El modelo de mundo de este recitado se aproxima más al de González de Castro que al Gil de Biedma, incluso parece reforzar la interpretación del primero.

Las versiones musicales del poema que se comentan a continuación son las siguientes: la ofrecida por Joan Manuel Serrat que es, además, autor de la música (https://www.youtube.com/watch?v=vAHFoybLcOo), la de Loquillo (https://www.youtube.com/watch?v=tiiriıgDVHw) con música de Gabriel Sopeña y la de Miguel Poveda (https://www.youtube.com/watch?v=CyDtqrATkoo) en la que los autores de la música son él mismo y Agustí Fernández. Se trata de tres intérpretes de estilos muy diferentes cuyas versiones cantadas del poema de Gil de Biedma son también muy diferentes. En el análisis del plano de la expresión de las versiones cantadas de un poema se debe prestar atención a la partitura y a la forma de cantar, pues ambos aspectos constituyen un todo que envía un mensaje global al oyente. La necesidad de fijarse en estos dos aspectos indica ya, de entrada, que las características del afepto en las versiones musicales presentarán, sin duda, importantes diferencias con respecto a las que contiene el texto del poema y también con respecto a las que contienen las versiones recitadas.

La versión musical de Joan Manuel Serrat fue compuesta ex profeso para el espectáculo teatral Las personas del verbo, presentado en el Teatre Lliure de Barcelona e interpretado por Mario Gas, Pep Munné e Iván Benet en 2017. Integrada en un espectáculo que giraba en torno a la figura del poeta, la composición de Serrat es una pieza para piano y violoncelo que funciona, casi exclusivamente, como acompañamiento de la voz del cantante, quien va perfilando la melodía de la pieza. Serrat consigue, con las notas sostenidas que le caracterizan, insistir en las ideas fundamentales del poema sin caer en dramatismos o en efectos alejados de la sobriedad. La licencia que se permite el cantautor es repetir, al terminar el último verso del poema, el título y el primer verso: "No volveré a ser joven, que la vida iba en serio". Con ello, el mensaje que llega al oyente con más fuerza es el de que "la vida va en serio" sin insistir en la vejez, en la decrepitud o en la muerte. Muy diferente es, pues, el afepto en esta pieza musical con respecto al poema original y a las versiones recitadas, y para valorarlo adecuadamente debe considerarse que se inserta en el seno de una representación teatral que busca conseguir que el espectador conozca a Gil de Biedma y su poesía. La composición no apela al melodrama, 
sino que busca el acercamiento del espectador al modelo de mundo del poeta desde una perspectiva que podría calificarse de "didáctica", pues se encuentra en el seno de una obra teatral cuyo objetivo es acercar la figura y la obra de Gil de Biedma a los lectores del siglo xxi. De alguna manera, Serrat parte del mundo de Gil de Biedma para acercarlo al lector contemporáneo.

Loquillo, uno de los más prestigiosos cantantes rockeros españoles, proporciona una versión de "No volveré a ser joven" en su línea musical. Es una composición ligera, alegre, en la que la música que suena está interpretada por un grupo y la melodía y la voz del cantante van a la par. Completamente distinta de la versión anterior, la de Loquillo transmite también la idea de que "la vida va en serio" pero con un toque de frivolidad. El oyente casi la puede interpretar como una advertencia sobre cómo funcionan las cosas pero sin mayor trascendencia ni necesidad de reflexionar sobre ello. Una vez más, aparece una modificación del silogismo afectivo, y curiosa en este caso. Los ejemplos analizados hasta ahora, como se ha visto, eran proclives a añadir solemnidad al mensaje del texto. La versión de Loquillo, en cambio, tiene un sentido distinto y su carácter performativo sobre el oyente es de orden diferente, pues puede conducirle a ser consciente de la importancia de la vejez y de la muerte pero, a la vez, parece invitarle a no tomárselo demasiado en serio.

Miguel Poveda es un bien conocido cantaor de flamenco español que goza de enorme prestigio. Se ha interesado también por otros géneros musicales, pero siempre teniendo el flamenco como referencia, y su versión del poema de Gil de Biedma se sitúa en esta perspectiva. Como se ha indicado, la música se debe a la colaboración del propio Miguel Poveda con Agustí Fernández. Se trata de un acompañamiento musical para piano que va pautando progresivamente la interpretación y es la voz del propio Poveda la que transmite la melodía. Su versión contiene recursos propios del cante flamenco, especialmente los alargamientos sostenidos de determinados sonidos en el interior de los cuales se producen variaciones tonales que transmiten el sentimiento, generalmente trágico, de quien canta. La canción evoca un cierto sufrimiento, en la línea del estilo del cantaor, que busca conmover al oyente y que, sin duda, lo consigue. Es decir, sentimos la vejez y la vida como dolor, muy propio del flamenco, que se apodera del poema y lo traslada a su propio universo genérico. Esta versión constituye otro desplazamiento del silogismo afectivo. 


\section{Conclusión: afepto y estudios fónicos}

El propósito de este trabajo ha sido interrogarse sobre la influencia de los elementos fónicos sobre el silogismo afectivo y el modelo de mundo que un texto porta y desde el que performa.

Como se ha señalado, existe una prolija bibliografía, en el ámbito de los estudios fónicos, sobre las variaciones que presenta el plano de la expresión en las operaciones de recitar o de musicar un poema. Estos trabajos han adoptado, casi siempre, una perspectiva estrictamente descriptiva. La corriente de la crítica del sabotaje, con su visión teórica acerca de los procedimientos que se utilizan para transmitir los modelos de mundo, permite relacionar los estudios descriptivos tradicionales con un punto de vista diferente que pone de relieve que las diferencias que se pueden observar en el plano de la expresión no son gratuitas, sino que están al servicio de la modelización, forman parte de una ideología. Puede, por tanto, considerarse que la crítica como sabotaje constituye un lugar de encuentro entre la descripción de los fenómenos y su posible interpretación teórica, entre funcionamiento retórico, modelo de mundo y mecanismo transaccional.

A través del análisis de cuatro versiones recitadas del poema de Gil de Biedma "Nunca volveré a ser joven" y de tres versiones musicales de este se ha podido demostrar que las variaciones fónicas por pequeñas que sean implican una transformación del silogismo. Se ha comentado, en primer lugar, la versión del autor en la creencia de que es la que más cerca estaría del "modelo de mundo" original de la composición, tanto más cuanto que el propio poeta ha declarado explícitamente que consideraba que ese era su mejor poema. Se ha visto que las demás versiones recitadas, formalmente diferentes entre sí y también distintas de la de Gil de Biedma, añadían siempre un cambio afeptivo al poema. Y, se ha podido poner de relieve que, en el caso de las versiones musicales, las modificaciones del afepto eran aún mayores.

En los estudios fónicos tradicionales o en las aproximaciones clásicas al recitado poético suele plantearse si estos cambios en la forma y los matices añadidos son "correctos" o no; pero lo que interesa aquí es algo bien distinto, porque lo que se ha tratado de demostrar es cómo las modificaciones sonoras del recitado varían el afepto, si provocan cambios, sean más sutiles o más profundos, en el modelo de mundo que un texto transmite, si son decisivas en el proceso de la modelización. Los ejemplos parecen demostrar que así es.

Este artículo pretende, modestamente, abrir una perspectiva de estudio dentro del ámbito de la crítica del sabotaje que se interesa por las características 
del afepto a la vez que muestra la posibilidad de diálogo entre esta y los estudios fónicos tradicionales, como una manera de insistir en la distancia que la teoría de Manuel Asensi marca con otros de los movimientos teóricos que ya intuyeron el poder performativo de los discursos, pero dejaron de lado los mecanismos que hacen que el texto literario, poético en este caso, ejerza ese poder.

\section{Bibliografía}

Asensi, Manuel. 20II. Crítica y sabotaje. Barcelona: Anthropos.

Asensi, Manuel. 2012. Modelos de mundo y lectores/as desobedientes. En Ferrús, Beatriz \& Zabalgoitia, Mauricio. La crítica como sabotaje de Manuel Asensi. Anthropos, Cuadernos de cultura crítica y conocimiento 237: I7-3I.

Asensi, Manuel. 20i6. Teoría de los modelos de mundo y teoría de los mundos posibles. Actio Nova: Revista de Teoría de la Literatura y Literatura Comparada Io: 38-55.

Cicerón. 2018. De Senectute. Madrid: Biblioteca Nueva.

Clavería, Gloria \& Poch Dolors (eds.). 20Io. Al otro lado del espejo. Barcelona: Ariel.

Ferrús, Beatriz \& Zabalgoitia, Mauricio. 20I2. La crítica como sabotaje de Manuel Asensi. Barcelona: Anthropos, Cuadernos de cultura crítica y conocimiento 237.

Frenck, Margit. 1997. Entre la voz y el silencio: la lectura en tiempos de Cervantes. México: Fondo de Cultura Económica.

Gil de Biedma, Jaime. 2002. Conversaciones. Barcelona: El Aleph.

Gil de Biedma, Jaime. 2006. Las personas del verbo. Barcelona: Galaxia Gutenberg.

Guillén, Jorge. I962. Poesía integral. Texto leído en Mons, Bélgica en 1962, al recibir el Grand Prix International de Poésie (en Guillén, I999: 735-749).

Navarro Tomás, Tomás. 1976. La voz y la entonación en los personajes literarios. México: México.

Pontón, Gonzalo. 20Io. Retórica y parodia epistolares: la "Letra" de Fernando del Pulgar sobre los males de la vejez. En Clavería, Gloria \& Poch, Dolors (eds.) Al otro lado del espejo. Barcelona. Ariel.

Riera, Carme. I988. La escuela de Barcelona. Barcelona. Anthropos.

Vega. María José. I992. El secreto artificio. Madrid: CSIC. 